\begin{tabular}{|c|c|c|}
\hline & $\begin{array}{l}\text { European Association for the } \\
\text { Development of Renewable Energies, Environment } \\
\text { and Power Quality (EA4EPQ) }\end{array}$ & $\begin{array}{l}\text { International Conference on Renewable Energies and Power Quality } \\
\text { (ICREPQ'12) } \\
\text { Santiago de Compostela (Spain), 28th to 30th March, } 2012\end{array}$ \\
\hline
\end{tabular}

\title{
Ferroresonant Configurations in Power Systems
}

\author{
V. Valverde, G. Buigues, A. J. Mazón, I. Zamora, I. Albizu \\ Department of Electrical Engineering \\ Faculty of Engineering of Bilbao, University of the Basque Country UPV/EHU \\ Alameda de Urquijo s/n, 48013 Bilbao (Spain) \\ Phone/Fax number:+0034 946014200, e-mail: victor.valverde@ehu.es
}

\begin{abstract}
Over the last decades, power disturbances have become an important factor on the increase throughout electrical networks, which can exert an important influence over power quality ratios. Amongst them, it is worth mentioning ferroresonance, which is a special case of resonance involving non-linear inductances that mainly affects the functionality of transformers. Its effects are characterized by high sustained overvoltages and overcurrents with maintained levels of current and voltage waveform distortion, producing extremely dangerous consequences. The first step against ferroresonance is always to prevent it from appearing, so it is important to identify those electrical configurations prone to the appearance of the phenomenon. Therefore, this paper analyzes different ferroresonant configurations that may take place in power systems, highlighting some of the most relevant aspects of each configuration.
\end{abstract}

\section{Key words}

Ferroresonance, Power Transformers, Voltage Transformers, Overvoltage, Overcurrent.

\section{Introduction}

Ferroresonance is a special case of disturbance that involves high levels of overvoltage and overcurrents distortion. In general, the word "ferroresonance" includes all the oscillatory phenomena that take place in an electric circuit comprising, at the least, a nonlinear inductance, a capacitance, a voltage source and low losses. The appearance of the ferroresonant phenomenon provokes important oscillations that may lead to catastrophic failures in the electrical power system. Furthermore, considering the large number of factors that may exert influence over its appearance, most of them hardly quantifiable, its consequences have a higher degree of severity. Consequently, although it has been a widely analysed phenomenon over the last century, it is currently a problem of the utmost importance in many electrical facilities.

In the last 25 years, the interest in this phenomenon has undergone an important increase in the field of research in electrical engineering. The constant evolution of electrical power systems has given rise to a significant increase in the amount of failures caused by ferroresonance. These failures have their origin in different causes, amongst which should be included the increased use of underground cables in primary circuits, single-phase operations, low-loss transformers, etc. [1].

The practical measures that can be taken in order to mitigate the ferroresonance are mainly based on specific solutions adapted for each foreseeable situation. Although there are several techniques for damping the ferroresonance oscillations [2], the first step against ferroresonance is always to prevent it from appearing, so it is important to identify those electrical configurations prone to the appearance of the phenomenon.

This paper analyzes each of these ferroresonant configurations, highlighting their special characteristics.

\section{Theoretical principles of ferroresonance}

\section{A. The ferroresonant circuit}

The ferroresonance phenomenon is associated with the coexistence, in the same electric circuit, of a non-linear inductance and a capacitor or capacitive load, connected either in series or parallel.

The effect of a nonlinear inductance is mainly found in both power and voltage transformers. Moreover, the capacitive effect necessary for the ferroresonance phenomenon can be provided by many elements. Some of the most common are: underground cables, overhead conductors, shunt capacitors, capacitive coupling of double circuit lines, transformer stray capacitance and grading capacitance of circuit breakers.

In addition, the presence of low-loss systems (i.e. lowresistive systems) increase the risk of ferroresonance appearance. If system losses are considerable, the energy 
supplied by the source may not be sufficient to sustain the ferroresonance. Some of the typical cases of low-loss systems are low-loss transformers' design, no-load or lowload transformers (e.g. voltage transformers) or transformers connected to low-loss circuits.

A combination of some of these elements and/or situations may provide the conditions for a ferroresonant circuit. Consequently, although this phenomenon is more frequent in distribution networks, due to the non-linear behaviour of transformers and the capacitance of the underground cables, it may also appear in high voltage networks.

\section{B. The ferroresonant phenomenon}

This phenomenon is characterised by showing at least two stable steady-state responses for a particular range of circuit parameters: a ferroresonant one and a normal operation one (non-ferroresonant). Furthermore, considering the dynamic characteristics of this nonlinear disturbance, the abovementioned ferroresonant response can be classified into four groups, according to the frequency content of the oscillation [3]:

- Fundamental mode: periodic oscillations at the fundamental frequency of the power system.

- Subharmonic mode: periodic oscillations at submultiple values of the fundamental frequency.

- Quasi-periodic mode: non-periodic oscillations with a discontinuous frequency spectrum.

- Chaotic mode: non-periodic chaotic oscillations with a continuous frequency spectrum.

The jump from one stable steady-state response to another one is highly dependent on the initial conditions of the system. As a result, a little variation in the transient state or in some of the parameters of the network may be the trigger that causes a sudden jump between two possible responses, leading to the appearance of one of the four ferroresonant modes previously mentioned. This way, the events that usually cause these kinds of variations can be classified as being in one of two main groups:

- Transient disturbances such as overvoltages, lightning, electrical faults or insulation failures.

- Switching operations in different elements of the power system, including transformers, capacitor banks, loads, etc.

These transient events may give rise to a ferroresonant oscillation, depending on the situation of the power system just before the ferroresonance starts. Among the aspects that have influence over this situation, it is worth mentioning the following ones:

- Power network characteristics: frequency and voltage levels, shortcircuit power, system grounding, etc.

- Properties of the voltage transformer's magnetic core, especially those related to the saturation characteristic, hysteresis loop and eddy currents losses.
- Possible residual fluxes in the voltage transformer's magnetic core.

- Circuit’s capacitance.

- Value of the voltage wave, in the instant of the transient disturbance or when the switching operation takes place.

Due to the difficulty in controlling and quantifying each and every one of these factors, ferroresonance is frequently regarded as an unpredictable or random phenomenon. Nevertheless, it can be characterised by certain aspects that are usually dangerous for people, as well as for the electrical equipment. Some of the symptoms that may give an idea about the ongoing ferroresonance are [4-5]:

- Overvoltages and overcurrents with high levels of harmonics.

- Sustained levels of distortion.

- Loud noise (magnetostriction).

- Misoperation of protective devices.

- Overheating.

- Electrical equipment damage.

- Insulation breakdown.

- Flicker.

\section{Ferroresonant Configurations in Power Systems}

There are several electric configurations that can lead to ferroresonant circuits in power systems. In 2003 D.A.N. Jacobson [6] identified seven different classes or categories of electrical systems prone to ferroresonance appearance. This section analyses each of these seven classes of ferroresonant systems. At the end, an eighth one has been included, regarding inductive grounded systems.

\section{A. Voltage transformer energized through the grading capacitance of open circuit breakers}

This is a typical case of high voltage systems where a circuit breaker is connected in series with an open circuit, having a phase-to-ground voltage transformer installed (Figure 1)

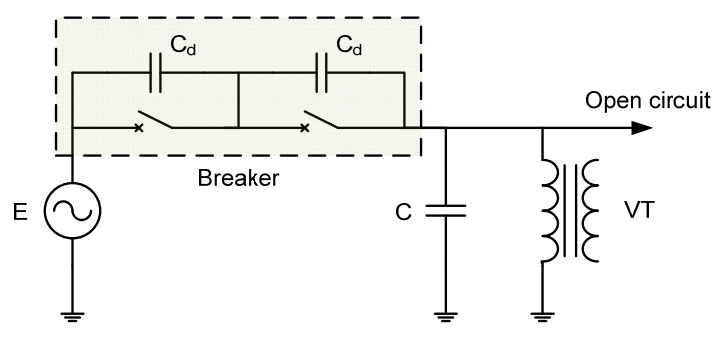

Fig. 1. Voltage transformer in series with an open circuitbreaker [3].

Opening the circuit breaker, phase-to-ground capacitance is discharged through the voltage transformer that is driven into saturation, provoking the ferroresonant oscillations. These oscillations are maintained by the 
energy supplied by the source through the circuit breaker grading capacitances [7-12].

The ferroresonant mode is generally fundamental or subharmonic $[8,12]$, and its overvoltage can reach values higher than 4 p.u. (peak value).

\section{B. Voltage transformer connected to an ungrounded neutral system}

When phase-to-ground voltage transformers are connected to an ungrounded neutral system, a ferroresonant circuit is formed between the nonlinear inductance of the voltage transformer and the phase-to-ground capacitance (Figure 2) $[4,13-22]$.

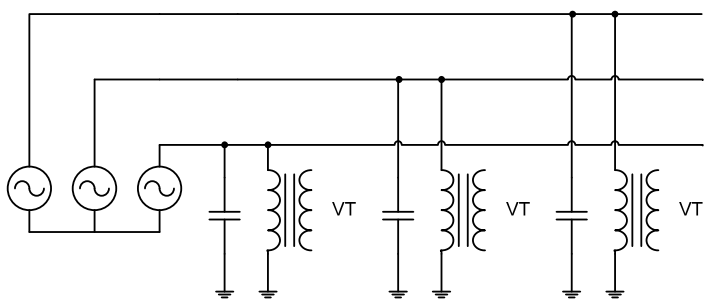

Fig. 2. Ferroresonance in phase-to-ground voltage transformers of an ungrounded neutral system [21].

This is a typical situation in ungrounded distribution systems with phase-to-ground fault detection protective devices. These protection systems require the presence of one phase-to-ground voltage transformer in each one of the three phases. The transformer primary windings are wyeground connected. The measure windings are ungrounded wye and the protective windings are open-delta connected, so the delta voltage is used to relay operation or to detect a phase-to-ground fault $[4,15-16,19]$.

Transient overvoltages or overcurrents due to switching operations or fault situations can initiate the ferroresonance phenomenon in one of the transformers. Values of ferroresonant overvoltages may exceed the normal phase-to-phase voltage.

Under these situations, the protective devices associated with these voltage transformers can identify the disturbance as an earth fault, causing undesired misoperations[15, 16].

The ferroresonant mode is usually fundamental, subharmonic or quasi-periodic.

\section{Capacitor voltage transformer}

The special design of capacitor voltage transformers (CVT) (Figure 3) makes them particularly prone to the ferroresonance, so they often present a ferroresonant suppression circuit. This circuit should not affect either the transient response or the accuracy of the transformer, only limiting the duration of the ferroresonant oscillations [21, 23-27].

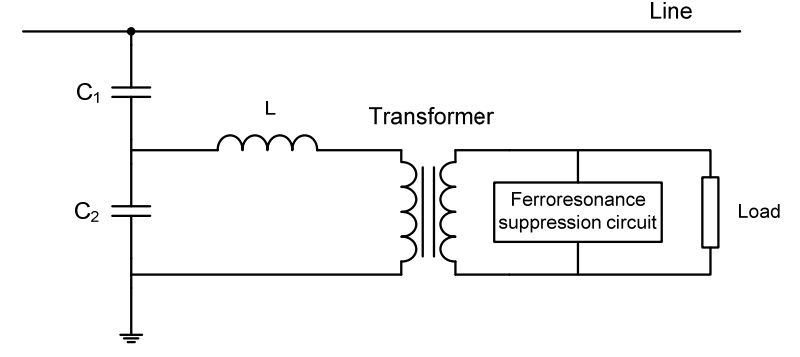

Fig. 3. Basic scheme of a capacitive voltage transformer.

Nowadays, there are mainly two types of ferroresonance suppression circuits in CVTs: Active Ferroresonance Suppression Circuits (AFSC) and Passive Ferroresonance Suppression Circuits (PFSC).

- AFSC: Its design is based on a series-parallel RLC filter.

- PFSC: Its design is based on a saturable inductor in series with a damping resistance.

AFSC are more effective in damping the ferroresonant oscillations than PFSC, although its influence on the transient response of the transformer is higher. Both systems usually incorporate surge protection devices.

In recent years, CVT Technology is being used in power substation design instead of traditional power transformers, in order to reduce the voltage level at some point of the line (e.g. rural power networks) [28]. This technique involves considerable cost savings compared to conventional alternatives, but its main drawback is related to being susceptible to ferroresonance [29-30].

\section{Power transformer supplied accidentally on one or two phases}

This type of electrical configuration is common in grounded-wye distribution systems (more specifically in rural systems) that feed three-phase power transformers under no-load or light-load conditions. The ferroresonance phenomenon appears after some type of disturbance or switching operation that provokes the power transformer of the installation to be fed on one or two phases (e.g. unipolar switchings, protection systems based on fuses, broken phase conductor,...) [13, 31-38]

If the primary winding of the power transformer is ungrounded, the ferroresonant circuit is created through the phase-to ground capacitance(s) of the open phase(s) (Figures 4 and 5)

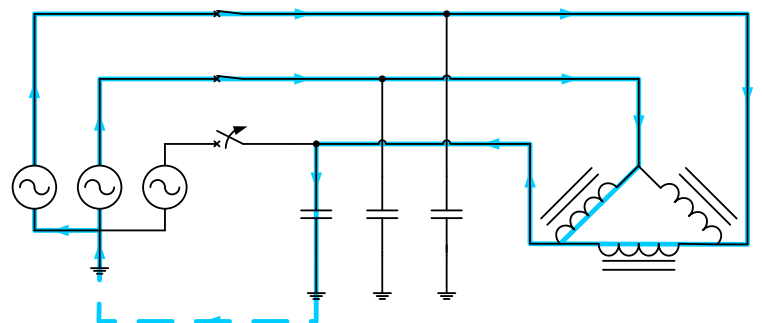

Fig. 4. Ferroresonant circuit in a transformer with delta primary connection [3]. 


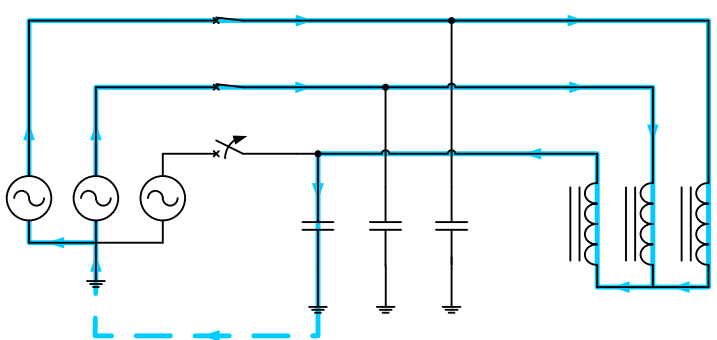

Fig. 5. Ferroresonant circuit in a transformer with ungroundedwye primary connection [3].

On the contrary, if the primary winding of the transformer is grounded, the ferroresonant circuit is created through the phase-to-phase capacitances (Figure 6).

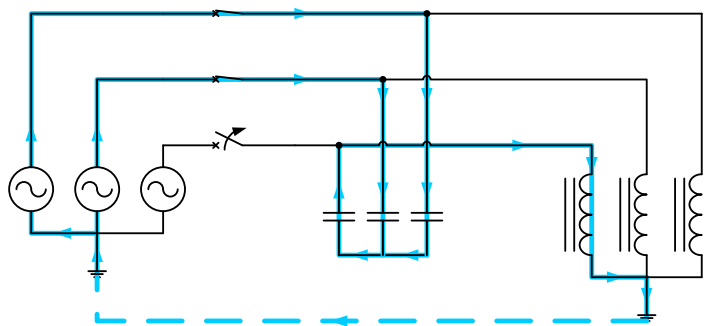

Fig. 6. Ferroresonant circuit in a transformer with grounded-wye primary connection [3].

If capacitances and primary windings have both the same ground connection (both ungrounded or both ground connected) the ferroresonant circuit does not appear.

In general, the ferroresonant mode is fundamental, subharmonic or chaotic.

\section{E. Power transformer supplied through a long transmission line cable with low short-circuit power}

Power transformers, under no-load or light-load conditions, are prone to be driven into ferroresonance when energized through a capacitive connection (long overhead lines or underground lines) by a source with a short-circuit power significantly lower than the transformer rated power [39-42].

This type of configuration is common in medium voltage networks (public, urban or industrial networks), after service restoration operations. It is also common in public medium voltage networks of significant length or an important ratio of underground cable.

Under these conditions, a parallel ferroresonant circuit is established between the line's capacitance and the transformer's magnetizing inductance. In these cases, ferroresonance is usually fundamental or quasi-periodic [3].

\section{F. Power transformer connected to a series compensated transmission line}

Series compensation systems counteract the impedance of transmission lines, reducing voltage variation and increasing the power transfer capability. Furthermore, the dynamic stability of the transmission grid is increased and the load between parallel transmission lines is balanced.

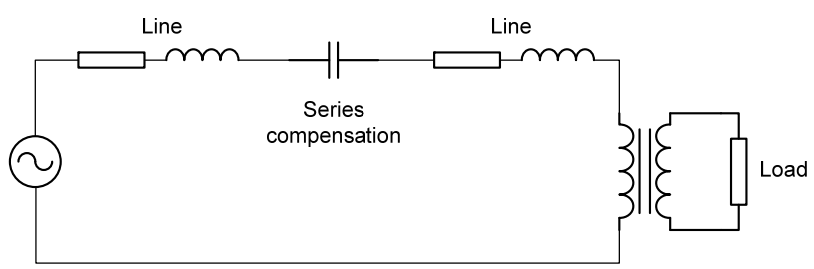

Fig. 7 Representative circuit of a series compensation in a distribution network [44].

The installation of capacitor banks in series-compensated transmission lines, along with the transformers of these lines, can induce the establishment of a ferroresonant circuit (Figure 7). The ferroresonant mode is generally fundamental or subharmonic [43-46].

G. Power transformer connected to a de-energized transmission line running in parallel with energized line(s)

It is possible to find ferroresonance cases in power transformers connected to de-energized transmission lines of considerable length, which run parallel to another energized line. Under these conditions, the capacitive coupling between both lines can drive the power transformer into ferroresonance [13, 47-51].

According to [50], the transmission lines must be high voltage lines (above $115 \mathrm{kV}$ ), which run at least 10 or 20 $\mathrm{km}$ in parallel.

The ferroresonant mode is generally fundamental or subharmonic (order 3) [49], and it depends largely on the length of transmission lines, being the subharmonic mode more common for lengths over $150 \mathrm{~km}$ [48].

\section{H. Inductive neutral networks}

Ferroresonance appearance may occur when a neutral system is connected to ground through an inductive impedance. Consequently, the ferroresonant circuit is formed between the ground-connected reactor and the phase-to-ground capacitances of the network (Figure 8).

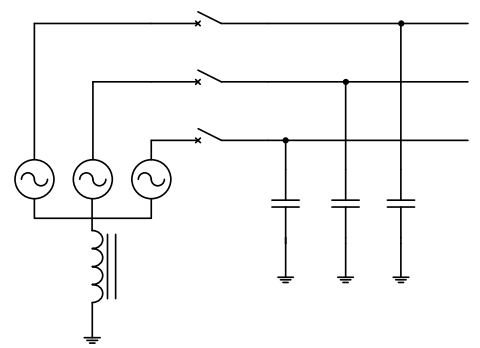

Fig. 8. Ferroresonant circuit in a MV network with Petersen coil [3].

In medium voltage networks, one of these neutral systems (Petersen coil) is used to limit ground fault currents and get the fault self-extinguishing. The ferroresonance appears after some type of disturbance that can drive the coil into saturation. 


\section{Measures against ferroresonance}

If the establishment of the ferroresonant circuit cannot be avoided, it is necessary to take some preventive measures that make it possible for this phenomenon to be damped. These measures basically consist of introducing some losses in the system, in order to make the energy supplied by the power source insufficient to maintain this phenomenon.

The most typical damping circuit consists on the permanent inclusion of a simple resistor in the transformer's secondary winding. A more advanced solution than the previous one consists of designing a damping circuit formed by a resistor connected in series with an LC filter or a saturable inductor [20, 52].

If the introduction of these losses is permanent, they may affect the efficiency of the installation in a considerable way, even provoking thermal failures under unbalanced situations. On the contrary, if the introduction of these losses were temporary, some sort of ferroresonance detection device would be necessary.

Nowadays, the current development level of these kinds of detection systems is quite limited, although during the last years, the production of detection techniques and devices has started to be increased [2].

\section{Conclusion}

Ferroresonance has been one of the most analyzed disturbances over the last years. Its consequences can be catastrophic for the electrical equipment and installations. Although there exist measures against this phenomenon, the first step is always to prevent it from happening, so it becomes necessary to know which are the situations prone to ferroresonance. This paper has presented the most common ferroresonant configurations in power systems.

\section{Acknowledgement}

The work presented in this paper has been supported, partially, by the Basque Government (Ref. IT532-10) and by the University of the Basque Country UPV/EHU (UFI 11/28).

\section{References}

[1] J. B. Wareing and F. Perrot, "Ferroresonance overvoltages in distribution networks", in Warning! Ferroresonance Can Damage Your Plant (Digest No: 1997/349), IEE Colloquium on Ferroresonance, Glasgow, Scotland, 1997, pp. 5/1-5/7.

[2] V. Valverde, A. J. Mazón, G. Buigues and I. Zamora, "Ferroresonance suppression in voltage transformers", in XIICLEEE - 12th Portuguese-Spanish Conference on Electrical Engineering, Azores (Portugal), March 2011.

[3] Ferracci, P.: "Ferroresonance", Group Schneider: Cahier ${ }^{\circ}$ 190, 1998, pp. 128

[4] R. Hoerauf and N. Nichols, "Avoiding potential transformer ferroresonant problems in industrial power systems", in Industrial and Commercial Power Systems Technical Conference, 1989, pp. 61-68.
[5] R.C. Dugan, M.F. McGranaghan, S. Santoso and H.W. Beaty, "Electrical Power Systems Quality”. McGraw Hill, 2002.

[6] D. A. N. Jacobson, "Examples of ferroresonance in a high voltage power system", in Power Engineering Society General Meeting, 2003, IEEE, 2003, pp. 1206-1212.

[7] R. G. Andrei and B. R. Halley, "Voltage transformer ferroresonance from an energy transfer standpoint", Power Delivery, IEEE Transactions on, vol. 4, pp. 17731778, 1989.

[8] D. Shein and S. Zissu, "Domains of ferroresonance occurrence in voltage transformers with or without damping reactors", in Electrical and Electronics Engineers in Israel, 1995., Eighteenth Convention of, 1995, pp. 1.5.2/1-1.5.2/5.

[9] D. A. N. Jacobson, D. R. Swatek, and R. W. Mazur, "Mitigating potential transformer ferroresonance in a $230 \mathrm{kV}$ converter station", in Transmission and Distribution Conference, 1996. Proceedings. 1996 IEEE, 1996, pp. 269-275.

[10] Z. Emin, B. A. T. Al Zahawi, and Y. K. Tong, "Voltage transformer ferroresonance in $275 \mathrm{kV}$ substation", in High Voltage Engineering, 1999. Eleventh International Symposium on (Conf. Publ. No. 467), 1999, pp. 283-286 vol.1.

[11] M. Sanaye-Pasand, H. Mohseni, S. Farhangi, A. RezaeiZare, and R. Iravani, "Effects of grading capacitors of CBs on inception ferroresonance in power transformers", in Universities Power Engineering Conference, 2004. UPEC 2004. 39th International, 2004, pp. 860-868 vol. 1.

[12] M. Val Escudero, I. Dudurych, and M. Redfem, "Understanding ferroresonance", in Universities Power Engineering Conference, 2004. UPEC 2004. 39th International, 2004, pp. 1262-1266 vol. 2.

[13] M. R. Iravani, A. K. S. Chaudhary, W. J. Giesbrecht, I. E. Hassan, A. J. F. Keri, K. C. Lee, J. A. Martinez, A. S. Morched, B. A. Mork, M. Parniani, A. Sharshar, D. Shirmohammadi, R. A. Walling, and D. A. Woodford, "Modeling and analysis guidelines for slow transients. III. The study of ferroresonance", Power Delivery, IEEE Transactions on, vol. 15, pp. 255-265, 2000.

[14] C. T. Weller, "Experiences with Grounded-Neutral, YConnected Potential Transformers on Ungrounded Systems", American Institute of Electrical Engineers, Transactions of the, vol. 50, pp. 299-316, 1931.

[15] H. S. Shott and H. A. Peterson, "Criteria for Neutral Stability of Wye-Grounded-Primary Broken-DeltaSecondary Transformer Circuits ", Transactions of the American Institute of Electrical Engineers vol. 60, pp. 997-1002, 1941.

[16] R. F. Karlicek and E. R. Taylor, "Ferroresonance of Grounded Potential Transformers on Ungrounded Power Systems", Power Apparatus and Systems, Part III. Transactions of the American Institute of Electrical Engineers, vol. 78, pp. 607-614, 1959.

[17] T. Van Craenenbroeck, D. Van Dommelen, N. Janssens, and F. Van De Meulebroeke, "Stability analysis of ferroresonant oscillations in networks with isolated neutral", in Devices, Circuits and Systems, 1995. Proceedings of the 1995 First IEEE International Caracas Conference on, 1995, pp. 41-45.

[18] N. Janssens, T. Van Craenenbroeck, D. Van Dommelen, and F. Van De Meulebroeke, "Direct calculation of the stability domains of three-phase ferroresonance in isolated neutral networks with grounded neutral voltage transformers", Power Delivery, IEEE Transactions on, vol. 11, pp. 1546-1553, 1996.

[19] D. R. Crane and G. W. Walsh, "Large mill power outages caused by potential transformer ferroresonance ", Industry 
Applications, IEEE Transactions on, vol. 24, pp. 635-640, July/Aug 1988.

[20] T. Van Craenenbroeck, D. Van Dommelen, and N. Janssens, "Damping circuit design for ferroresonance in floating power systems", European Transactions on Electrical Power, vol. 10, pp. 155-159, May/June 2000.

[21] M. Sanaye-Pasand, A. Rezaei-Zare, H. Mohseni, S. Farhangi, and R. Iravani, "Comparison of performance of various ferroresonance suppressing methods in inductive and capacitive voltage transformers", in Power India Conference, 2006 IEEE, 2006, p. 8 pp.

[22] W. Piasecki, M. Florkowski, M. Fulczyk, P. Mahonen, and W. Nowak, "Mitigating Ferroresonance in Voltage Transformers in Ungrounded MV Networks", Power Delivery, IEEE Transactions on, vol. 22, pp. 2362-2369, 2007.

[23] B. S. Ashok Kumar and S. Ertem, "Capacitor voltage transformer induced ferroresonance--causes, effects and design considerations", Electric Power Systems Research, vol. 21, pp. 23-31, 1991.

[24] S. K. Chakravarthy and C. V. Nayar, "Ferroresonant oscillations in capacitor voltage transformers", Circuits, Devices and Systems, IEE Proceedings -, vol. 142, pp. 3036, 1995.

[25] M. R. Iravani, X. Wang, I. Polishchuk, J. Ribeiro, and A. Sarshar, "Digital time-domain investigation of transient behaviour of coupling capacitor voltage transformer", Power Delivery, IEEE Transactions on, vol. 13, pp. 622629, 1998.

[26] M. Graovac, R. Iravani, W. Xiaolin, and R. D. McTaggart, "Fast ferroresonance suppression of coupling capacitor voltage transformers", Power Delivery, IEEE Transactions on, vol. 18, pp. 158-163, 2003.

[27] F. B. Ajaei, M. Sanaye-Pasand, A. Rezaei-Zare, and R. Iravani, "Analysis and Suppression of the Coupling Capacitor Voltage Transformer Ferroresonance Phenomenon", Power Delivery, IEEE Transactions on, vol. 24, pp. 1968-1977, 2009.

[28] H. G. Sarmiento, R. de la Rosa, V. Carrillo, and J. Vilar, "Solving electric energy supply to rural areas: the capacitive voltage divider", Power Delivery, IEEE Transactions on, vol. 5, pp. 259-265, 1990.

[29] L. Bolduc, B. Bouchard, and G. Beaulieu, "Capacitive divider substation", Power Delivery, IEEE Transactions on, vol. 12, pp. 1202-1209, 1997.

[30] M. Sanaye-Pasand, R. Aghazadeh, and H. Mohseni, "Ferroresonance occurrence during energization of capacitive voltage substations", in Power Engineering Society General Meeting, 2003, IEEE, 2003, p. 606 Vol. 2.

[31] E. Clarke, H. A. Peterson and P. H. Light, "Abnormal Voltage Conditions in Three- Phase Systems Produced by Single-Phase Switching", American Institute of Electrical Engineers, Transactions of the, vol. 60, pp. 329-339, 1941.

[32] G. G. Auer and A. J. Schultz, "An Analysis of 14.4/24.9Kv Grounded-Wye Distribution System Overvoltages", Power Apparatus and Systems, Part III. Transactions of the American Institute of Electrical Engineers, vol. 73, pp. 1027-1032, 1954.

[33] F. S. Young, R. L. Schmid, and P. I. Fergestad, "A Laboratory Investigation of Ferroresonance in CableConnected Transformers", Power Apparatus and Systems, IEEE Transactions on, vol. PAS-87, pp. 1240-1249, 1968.

[34] E. C. Lister, "Ferroresonance on Rural Distribution Systems", Industry Applications, IEEE Transactions on, vol. IA-9, pp. 105-111, 1973.

[35] D. R. Smith, S. R. Swanson and J. D. Borst, "Overvoltages with remotely-switched cable-fed grounded wye-wye transformers", Power Apparatus and Systems, IEEE Transactions on, vol. 94, pp. 1843-1853, 1975.
[36] R. A. Walling, "Ferroresonance in low-loss distribution transformers", in Power Engineering Society General Meeting, 2003, IEEE, 2003, p. 1222 Vol. 2.

[37] R. C. Dugan, "Examples of ferroresonance in distribution", in Power Engineering Society General Meeting, 2003, IEEE, 2003, p. 1215 Vol. 2.

[38] P. Picher, L. Bolduc, B. Girard and V. N. Nguyen, "Mitigation of Ferroresonance Induced by Single-Phase Opening of a Three-Phase Transformer Feeder", in Electrical and Computer Engineering, 2006. CCECE '06. Canadian Conference on, 2006, pp. 482-485.

[39] W. B. Gish, W. E. Feero, and S. Greuel, "Ferroresonance and Loading Relationships for DSG Installations", Power Delivery, IEEE Transactions on, vol. 2, pp. 953-959, 1987.

[40] C. Kieny, "Application of the bifurcation theory in studying and understanding the global behavior of a ferroresonant electric power circuit", Power Delivery, IEEE Transactions on, vol. 6, pp. 866-872, 1991.

[41] T. A. Short, J. J. Burke, and R. T. Mancao, "Application of MOVs in the distribution environment", Power Delivery, IEEE Transactions on, vol. 9, pp. 293-305, 1994.

[42] T. Ta-Peng and N. Chia-Ching, "Analysis of ferroresonant overvoltages at Maanshan Nuclear Power Station in Taiwan", Power Delivery, IEEE Transactions on, vol. 21, pp. 1006-1012, 2006.

[43] R. Gagnon, P. Viarouge, and G. Sybille, "Study of ferroresonance in a series compensated network", in Electrical and Computer Engineering, 1995. Canadian Conference on, 1995, pp. 447-452 vol.1.

[44] R. A. Barr and D. Platt, "Modelling and mapping ferroresonant states in series compensated distribution and subtransmission lines", Power Delivery, IEEE Transactions on, vol. 11, pp. 931-939, 1996.

[45] R. Gagnon, P. Viarouge, G. Sybille, and F. Tourkhani, "Identification of ferroresonance as the cause of SVC instability in a degraded series compensated network", in Power Engineering Society Winter Meeting, 2000. IEEE, 2000, pp. 1377-1382 vol.2.

[46] O. C. Parks, A. A. Girgis, and M. E. Frick, "Simulating ferroresonance in a series compensated distribution network", in Harmonics and Quality of Power, 2000. Proceedings. Ninth International Conference on, 2000, pp. 162-167 vol.1.

[47] E. J. Dolan, D. A. Gillies, and E. W. Kimbark, "Ferroresonance in a Transformer Switched with an EHV Line", Power Apparatus and Systems, IEEE Transactions on, vol. PAS-91, pp. 1273-1280, 1972.

[48] D. M. German and A. E. Davies, "Ferroresonance on EHV transmission systems", 1978 IEEE PES Winter Meeting, Paper No. A78 116-6, Feb 1978.

[49] R. H. Brierley, A. S. Morched, and T. E. Grainger, "Compact right-of-ways with multi-voltage towers", Power Delivery, IEEE Transactions on, vol. 6, pp. 16821689, 1991.

[50] D. A. N. Jacobson, L. Martí, and R. W. Menzies, "Modelling ferroresonance in a $230 \mathrm{kV}$ transformerterminated double-circuit transmission line", in Proc. of the 1999 Intl. Conf. on Power system Transients (IPST), 1999, pp. 451-456.

[51] R. Saravanaselvan, R. Ramanujam, K. Al-Anbarri, and S. L. Naresh, "Ferroresonant oscillations in a transformer terminated line due to an energised parallel line on the same right-of-way", Generation, Transmission and Distribution, IEE Proceedings-, vol. 152, pp. 475-482, 2005.

[52] J. Horak, "A review of ferroresonance", in Protective Relay Engineers, 2004 57th Annual Conference for, 2004, pp. 1-29. 